\title{
Modeling complex human-environment interactions: The Grand Canyon river trip simulator
}

\author{
Catherine A. Roberts*, Doug Stallman, Joanna A. Bieri \\ Department of Mathematics and Computer Science, College of the Holy Cross, \\ Worcester, MA 01610, USA
}

\begin{abstract}
Understanding the impacts of human recreation on natural resources is of critical importance in constructing effective management strategies. The Grand Canyon River Trip Simulator is a computer program that models complex, dynamic human-environment interactions in the river corridor of the Grand Canyon National Park. The system consists of a database and simulator engine. The database contains 487 trip diaries that report all stops for activities and camping along the 447 kilometer Colorado River corridor within the purview of the National Park Service. The computer simulation employs statistics and artificial intelligence in creating an individual-based modeling system. This simulation system successfully models the recreational rafting behavior and captures the decision making of rafting parties as they responsively seek to optimize their experience. The model allows the Park managers to assess the likely impact of various alternative management scenarios for rafting trips on the Colorado River. The Grand Canyon River Trip Simulator advances our abilities to model complex systems in the context of human-environment interactions. It may serve as a suitable template for modeling a suite of other complex adaptive systems including ecosystems.
\end{abstract}

*Corresponding Author. Tel: 1-508-793-2456; fax: 1-508-793-3530

Email: croberts@holycross.edu (C. Roberts) 
Keywords: Agent-based modeling, Individual-based models, Simulation, Grand Canyon National Park, Recreation, Human-environment interactions

\section{Introduction}

The Grand Canyon in the western United States is well-known as one of the natural wonders worldwide. Besides viewing the spectacular canyon landscape, an extremely attractive recreational activity in the Grand Canyon National Park is river-rafting on the Colorado River. The park allocates use through special licenses to sixteen commercial river outfitting companies, and maintains a waiting list for noncommercial (private) permits. Trips range from 3 to 22 days. Some trips include an exchange, where passengers hike or helicopter in or out of the canyon (only possible at two locales). Boats enter the river at Lees Ferry and proceed up to $447 \mathrm{~km}$ to their take-out location, which can be either Diamond Creek or Pearce Ferry (in Lake Mead). Along the way, boaters can choose from many different activities and campsite locations, which may include hiking, swimming or archeological cultural sites. River trips are governed by launch schedules, which control the day trips begin, the nature of any passenger exchanges that occur, and the day and location where the trip ends. Implicit in the launch schedule are the number of user days that are affiliated with each individual trip. A user day is one person on the river for one day and it is the measurement used by the park to control the number of people allowed on the river. While the allocation of user days to the various rafting outfitters is fixed by contract, the managers of the Grand Canyon National Park can modify launch schedules to influence the patterns of rafting traffic on the Colorado River, and thus to optimize the flow patterns on the river. 
Some 22,000 recreational users raft the river annually. This number does not include the crew on commercial trips, the administrative use, or the science trips that also spend time on the river. To get a sense of the popularity of river rafting in the Grand Canyon, the current waiting list for private river permits is about 12 years long, whereas commercial trips need to be reserved one or two years in advance. With an increase in the demand for access to the Grand Canyon for rafting activities, there is a concern that a higher volume use of the river could result in either a negative impact on the natural resource or a decline in the wilderness experience desired by the users. Moreover, the long waiting list clearly indicates an increasingly severe problem of accessibility. Ideas for resolving these issues vary greatly. There are several constituent groups passionately involved in the political issues surrounding recreational use of the Colorado River within the Grand Canyon National Park. While some groups demand increased access to the river, others request reducing the impact of human use. While some groups support the use of motorized watercraft, others are against it. The issues of access and impact are complex, and the Grand Canyon National Park has conducted numerous scientific studies to help aid decision making (for example, see Brian and Thomas, 1984; Hall and Shelby, 2000; Kearsley and Quarteroli, 1997; O'Brien and Roberts, 2000). The Colorado River Management Plan (CRMP, 1989) is the guiding document that sets limits on recreational use within the park. A key component of the 1989 CRMP included the suggestion that a computer model be designed that could directly assist park managers. The belief was that a computer model could offer insight into the dynamics of human/environment interactions that could inform the management of this critical setting. The Grand Canyon River Trip Simulator Project (GCRTSim) is one component of the most recent round of sponsored research intended to assist park managers in updating the 
CRMP (see, for example, Bieri and Roberts, 2000; Gimblett et al., 2000b; Hall and Shelby, 2000; Jalbert, 1993; O’Brien and Roberts, 2000; Roberts and Gimblett, 2001).

Shechter and Lucas (1978) developed the Wilderness Use Simulation Model (WUSM) to simulate hikers' use of trail segments, cross-country travel routes and camping areas in order to estimate the numbers of encounters and potential conflicts among parties. WUSM was subsequently adapted for application to rafting parties on the Colorado River (Underhill and Xaba, 1983; Underhill et al., 1986; Borkan and Underhill, 1989). The effects of launch schedules and variable water flows were major input components of the river trip model. The model projected the rates of raft travel and the numbers of encounters. The WUSM model lacked many details of the actual river trip situation, however, having fixed trip itineraries with only launch date and trip length as variables. Outputs were restricted to aggregate summaries of the frequencies of encounters among raft parties. In contrast, the Grand Canyon River Trip simulator consists of an extensive database of comprehensive trip diaries completed during the 1998, 1999 and 2000 rafting seasons when the water flow rates averaged 19,000 cubic feet per second (considered a "typical" flow regime for the Colorado River). In addition, GCRTSim is an integrated statistical and artificial intelligence-based computer simulator that models complex human-environment interactions over multiple spatiotemporal scales. This paper discusses the development, calibration, and application of GCRTSim. While a fuller testing of the model is an on-going activity, the model is being used as a management tool in the Grand Canyon National Park.

\section{Background for the modeling approach}


The value of simulation methods as a tool for understanding and managing natural resources is evident. The cost of implementing a policy change that subsequently fails is not only measured in dollars, but also in the resulting injury to the cultural and natural resources. If a simulation model can provide insight into the potential consequences of a policy change under consideration, then the potential to avoid costly misjudgments is enhanced. We will provide here some discussion of the history of the development of tools to model complex humanenvironment interactions. A more comprehensive review can be found in Gimblett et al. (2000a, 2000b).

While many computer simulation efforts have focused on biophysical environmental processes (e.g., Goodchild et al. , 1993; Wu and Levin, 1997), the human dimension of environmental systems has not been fully addressed. Many of these simulation modeling efforts employ a number of artificial intelligence techniques combined with Geographic Information System (GIS) functions to address human-environment interactions (e.g. Green, 1987; Ball, 1994; Slothower et al., 1996; Gimblett et al., 1996a, 1996b; Briggs et al., 1996). Exploratory studies (e.g. Berry et al., 1993; Gimblett et al., 1994; Saarenmaa et al., 1994; Tobler, 1979 ; Itami,1988, 1994) have suggested the use of cellular automata as a method for simulating dynamic environmental processes over large scale landscapes, and applications of this approach have been successfully demonstrated (e.g. Green et al. , 1987; Manneville et al., 1989).

Individual-based models have recently been applied to develop spatially-explicit models of ecological phenomena. Individual-based models are "organisms-based models capable of modeling variation among individuals and interactions between individuals" (Slothower et al. , 1996; Wu and Loucks, 1995; Wu, 1999). This approach offers potential for studying complex behavior and human/landscape interactions within a spatial framework (Drogoul and Ferber, 
1995; Findler and Malyankar, 1995). One form of individual-based modeling approaches is agent-oriented programming. Two good sources of information on agent-oriented programming are Cavendon et al (1996) and Weiss (1999). Included in this approach is the study of complex adaptive systems, where tools and techniques are being developed to study emergent behavior, as in Swarm (Hiebeler, 1994; Langton et al., 1995), Echo (Jones and Forrest, 1993; Forrest and Jones, 1994), GENSIM (Anderson and Evans, 1995), and RBSim (Gimblett et al., 2000a; Bishop and Gimblett, 1999).

An agent is "a computational entity that can be viewed as perceiving and acting upon its environment and that is autonomous in that its behavior at least partially depends on its own experience. As an intelligent entity, an agent operates flexibly and rationally in a variety of environmental circumstances given its perceptual and effectual abilities. Behavioral flexibility and rationality are achieved by an agent on the basis of key processes such as problem solving, planning, decision making, and learning" (Weiss, 1999). The approach in GCRTSim is to represent rafting trips as individual, rational entities. Multiple agents dynamically interact with each other within their environment to work towards optimizing their experience on the river.

The combination of spatially-explicit individual-based models, reactive agents, artificial intelligence (AI) and Geographic Information Systems (GIS) offers a powerful alternative to previous modeling techniques for exploring emergent, complex, evolutionary processes. While the methodology would be of interest to many disciplines, the ability to model the differences among groups, local interactions and variability over time and space, as well as the complex, decision making processes of individuals, makes our approach an ideal technique for simulating recreation behavior and interactions in contexts like that of the Colorado river rafting trips. 


\section{Data and methods}

The goal of GCRTSim is two-fold -- to improve understanding of the current conditions and to predict the possible outcomes of changes to the current set of regulations guiding river rafting traffic. Trip diaries were collected from rafting parties and used to inform the Park Service of the frequency of use of various camping and attraction sites. Interviews with expert river guides also provided insight into the logic employed by various types of river guides as they manage their trips down river. Each research team member joined at least one Colorado River trip. Relationships were formed with the leaders of the various constituent groups: the managers and staff from the Grand Canyon National Park, the Grand Canyon River Outfitters Association, the Grand Canyon Private Boaters Association, and Colorado River Guides Association. These efforts informed the development of an artificial intelligence and statisticalbased computer simulation model of rafting traffic along the Colorado River.

\subsection{The data set}

We collected data by distributing and collecting trip diaries and by conducting lengthy interviews with expert trip leaders. We looked for trends that would lead to information about the key aspects of the river that needed to be modeled. Beginning in July 1998 and ending in December 2000, trip leaders were asked to complete trip itineraries called Trip Reports. These trip reports listed the time in and time out for every reasonable location -- we identified 250 sites between the launching area at Lees Ferry and Diamond Creek (the location where the National Park Service stops monitoring people and activity on the Colorado River).

Analysis conducted on the 1998 Trip Report data concluded that the trip types listed in Table 1 appropriately capture the similar behavior among trips of similar length with the same 
propulsion (Bieri and Roberts, 2000; Roberts and Gimblett, 2001). These four distinct trip types refer to the days on the river between launch at Lees Ferry (river mile zero) and either take-out or passing Diamond Creek (river mile 225.7). It is noted that these categories do not distinguish between private and commercial trips, it was determined that most private trips are long oar trips and that occasional long oar trips run by a commercial company tend to behave with enough similarity that grouping them together is appropriate. Table 2 shows the breakdown of the 487 Trip Reports (again, collected during a "typical" flow regime).

Inaccuracies and incomplete information are something that we had to confront in this study. By having river experts enter the data, their judgment was used on occasion to clarify items entered onto the trip report. For example, if a lunch stop was recorded with a time-in but no time-out, we would use the overall average time spent on lunch stops to extrapolate a reasonable time-out for the data item. Trip reports were sometimes sent to us with the locations of camps and activities, but no stopping times. We still entered this data into our database for use in computing the popularity of the camp and attraction sites, although those trips could not be used when computing the average time spent at the sites. When possible, follow-up phone calls were made to the commercial companies or to the private permit holders to clarify items on some trip reports.

This database of trip reports is the most comprehensive set of recreational use pattern data ever collected for the Colorado River within the Grand Canyon National Park. The extent of the popularity of some campsites, for example, was unknown prior to the collection of this data. With this information, guides and park managers can identify the most impacted sites for the first time. These trip reports are essential for designing the simulated river environment. For example, they are used to determine boat speeds, popularity of attraction and campsites, and the 
probabilities that trips will engage in layovers (spending more than one night camping at the same site). They are also used to derive estimates on the length of time trips stay at sites along the river corridor.

\subsection{Boat speed}

Boat speed is defined here as the sum of the speed of the Colorado River (which is based on the instantaneous water flow rate governed by water releases at Glen Canyon Dam) and the speed of the boat (propulsion by motor or oar). Over the time period that is represented in our database, the average water discharge from Glen Canyon Dam was 19,000 cubic feet per second (cfs) (http://www.usgs.gov). This is considered to represent a typical flow regime (Jalbert, personal communication), so we consider GCRTSim to simulate seasons within this normal range. Trip reports from unusual flow periods, such as from an experimental 8,000 cfs period during a portion of 2000 , were not included in this study although could be used to expand the capabilities of GCRTSim (Roberts and Bieri, 2001). Using the standard equation that boat speed equals the distance traveled divided by the elapsed time, the database of trip reports was queried to determine the boat speed for each time segment that the trip spent on the river in between successive stops.

Once the average speeds for each river segment of an individual trip were computed, the overall speeds were estimated. Over each ten mile stretch of river, computed individual trip speeds from that stretch were averaged together, grouped by trip type (short/long, motor/oar). Thus, each ten mile segment of the river had associated with it an average speed for each of the four trip types. These points were plotted on a set of axes and a smooth polynomial fit was used to create the graphs shown in Figure 1. In some reaches of the Colorado River, the trips go faster 
as a result of the narrowing of the canyon and subsequent speeding up of the river water. There are also sociological influences on the boat speed. For example, in reaches of the river with outstanding views and multiple attraction sites, the overall speed could slow down as the trip leader chooses to shift down the pace of the trip. At the end of the trip, either to make up lost miles or because there are fewer attraction sites, one can see that trips tend to move faster downstream.

The simulator uses these mathematical functions to get a first estimate of the speed of a trip, based on trip type. The functions are stochastic in that they give both a speed and a standard deviation that is taken into consideration each time the model samples the function. Consequently, each trip will have a unique buy representative speed as it travels down the simulated Colorado River.

\subsection{Analysis of attraction sites}

To simulate the decision making of trips, the Trip Report database provided popularity data for attraction and camp sites that could be analyzed by trip type. For example, Table 3 lists the overall most popular attractions, where visitors enjoy hiking, swimming and cultural sites. Some sites are equally popular, but others seem to be more attractive to certain trip types. For example, trips of longer duration enjoy greater flexibility, in that they have more time to spend

off-river engaged in activities than would a trip of shorter duration. A site such as Tapeats (mile 133.8) is generally appealing to longer trips because it offers a long hike option. Tapeats also offers a short hike option, which is more likely to be selected by a trip with less time available for recreation. Analysis of the Trip Report database provides information on how each trip type chooses attraction sites. Moreover, when a site offers multiple hike options, breakdowns are 
tabulated that list the probabilities that a trip of a given type will choose any one of the various options. This information provides a guide for the intelligent agent to consult when weighing various options during a simulation. For example, when a trip agent makes a daily plan in the morning, it scans the upcoming reach of river and rank-orders attraction sites based on their popularity. The decision to stop at an attraction is based, in part, on how attractive it is to the individual trip. The probability of a trip choosing a popular site is weighted based on the historical popularity of the site. Moreover, the time spent at a site is also based initially on the average amount of time spent for that particular trip type.

\subsection{Analysis of campsites}

Analysis of the Trip Report database also provides insight into the popularity of campsites (Table 4). The popularity of the camps can be differentiated among the four trip types. There is more variability among trip types in regard to campsite selection than there is in regard to attraction site selection. This is because trips of different lengths segment the river differently and find themselves in completely different reaches of the river on different nights. Moreover, some campsites can't be accessed by the larger motor watercraft and others are too small to serve as camps for larger group sizes. While some of this information came from other scientific studies (Brian and Thomas, 1994; Kearsley and Quarteroli, 1997, O’Brien and Roberts, 2000), much of it came out of the analysis of real-world data housed in the Trip Report database.

Another important consideration to capture the real-world behavior in regards to camping revolves around layovers. A layover is when a trip chooses to camp for two or more subsequent nights at the same site. As will be seen later, the artificial intelligence planning function for trips that engage in layovers is more complex than that for trips that do not engage in layovers. The 
probability of a trip that is 14 days long will have a layover is 0.25 , whereas a trip of 18 day duration is $100 \%$ likely to engage in at least one layover. Moreover, campsites are not evenly distributed over the river corridor - there are reaches where campsites are plentiful and others where fierce competition comes into play. Communication and cooperation between trips plays a large role in how campsite choices are made. Each of these factors - specialized layover behavior, competition and cooperation around campsite selection - plays a role in the algorithms of this computer simulation.

\subsection{Communication and cooperation between trips}

When two trips find themselves passing on river or stopping at an attraction site together, communication takes place. Typically, the discussion between two trips revolves around sharing their future plans - especially for camping. There is some tension between commercial and noncommercial groups and also between oar and motor powered trips. Experience gained by the authors from participating in river trips and also from extensive interviews with experienced river guides has contributed to the creation of the simulated "rules" for handling communication between two river parties.

In the simulation, when trips find themselves occupying the same location (either on or off river), communication ensues. A conversation is not guaranteed, since expert knowledge has been used to establish the probabilities of communication happening for different types of trip interactions. When it does occur, essentially the two trips swap their campsite wish-lists with each other and a module in the program is called to sort out any conflicts and to determine the result of the communication. 


\subsection{Creating the river environment}

The goal of GCRTSim is to simulate a realistic river environment that can be used to test new launch schedules. To create this river environment, we divided the river corridor (447 km) into 90-meter "cells" and identified the locations of sites along the river corridor. Each site is classified as a camp and/or activity site and appropriate attributes are assigned.

\subsection{Simulating decision making}

In addition to modeling the physical river itself, we also simulate the decision making of guides. Our method is a hybrid approach involving expert knowledge, intelligent agents, fuzzy logic, statistical analysis, autocorrelation and other techniques. Guides navigate the river and make dynamic responses to their environment. Their decisions are constrained, in some sense, by the type of trip that they are running. The type of watercraft certainly impacts the behavior motorized watercraft can move more quickly down river and thus provide the guide with more flexibility in designing each day's activities. This is in contrast to oar-powered craft that have a reduction in flexibility in management of their daily activities due to the fact that these trips must spend more time each day traveling on river. For example, if a motor-powered trip finds that its planned campsite is occupied late in the afternoon, it may be able to travel down river late to secure an unplanned and unoccupied campsite. There may not be enough time for an oarpowered trip to do so. On the other hand, the increased time available to a longer trip would present a guide with a broader menu of choices, whereas a shorter trip length is more restrictive. Since motor trips are typically shorter in duration than oar trips, less time is available to spend off-river. Because oar trips typically have more days in the Canyon, they have time to engage in more substantial off-river activities. 
The simulation uses intelligent agents - each trip is treated as an individual capable of making its own plans and adjusting those plans as it travels down the river. An artificial intelligence algorithm has been developed to guide each intelligent agent (e.g. trip) down the Colorado River in a manner consistent with our understanding of reality. This enabled us to develop an artificial intelligence- and statistically-based computer simulation. The simulation can approximate a trip's behavior under a wide range of conditions and thus provide insight into the potential consequences of a launch schedule change before it is implemented.

Recall that there are four trip types: long and short oar, and long and short motor trips (see Table 1). Within each trip type, there is still room for much variation in behavior. Each individual trip in the simulation is its own intelligent agent. While its initial plan for the day is based on a statistical reading of the collected real-world data, as the trip moves down river, it reacts to the complex environment around it. Sampling from the tables that list the frequency of visitation for activities and camps is random and weighted with other factors in the decision making algorithm. Plans are modified based upon the reaction of the individual trip to the information it has gathered. For example, if two trips encounter each other and communicate, they may learn that they were both targeting the same campsite for the upcoming evening. In this event, the two trips negotiate a compromise. This compromise is based on our understanding of the real-world dynamic that occurs when trips communicate with each other. In the event that one trip is motorized, it has more flexibility to reach a broader set of campsites. Consequently, to resolve the conflict, the motorized boat would defer to the oar trip and choose an alternate campsite for the evening. In the event that both trips are oar powered, then a comparison ensues of each trip's campsite "wish list" and the best choices are made. 
The model uses techniques such as autocorrelation in the sense that the activity at a certain site is a function of the activity there and a weighted sum of the activity at the surrounding sites. Consequently, the behavior of one trip is a result of the dynamics of the entire population of trips, as well as being a function of the extensive spatial variables that describe the environment.

\section{Simulation algorithms}

When a simulated trip is launched, a number of things occur. First, the trip makes some tentative plans for the day. These plans include selecting and ranking a set of campsites (based on their trip type) that are within a reasonable distance. The target distance that a trip tries to travel each day depends primarily on its trip length, but also on any special activity sites that might be encountered during the day. The plan also includes identifying some attraction sites. The most popular attraction sites, called key attraction sites, are always a part of any trip's daily plan (even though scenarios may occur during the day that result in a trip not engaging in this activity, it always starts out as part of the plan). A calculation is done that estimates the time that will be needed to bring the watercraft to the target campsite range, so that an estimate of the amount of off-river time is in hand. This off-river time is then distributed, in the daily plan, to one or more attraction sites.

Once the plan is in place, the simulated trip begins to travel down the river. As it enters each individual 90-meter cell, the boat speed is sampled off of the function derived from the realworld data for that trip type (see Figure 1). As the day progresses, the plan is constantly compared with the current conditions and any necessary adjustments are made. For example, if a trip reaches a planned attraction site and it is crowded with other trips, then the trip may or may 
not decide to stop there. There is a higher probability that the trip will endure crowding at one of the key attraction sites. At a less popular attraction site, crowding will not be tolerated under most circumstances because there are other choices available to the trip which is always trying to maximize the opportunities for solitude and a wilderness experience. When the trip arrives at an attraction site, it also recalculates the time needed to reach the target campsite. If sufficient time remains to visit the site, then the probability of stopping rises. Another factor that comes into the decision is associated with how long the trip decides to stay at a site. In order to understand how the artificial intelligence works in GCRTSim, one first needs to understand how the trips are configured upon launch, and how the trips make plans and act them out as they move down the river. The description provided here corresponds to version 3.0 of GCRTSim.

\subsection{Trip configuration}

When a trip initiates with launch at Lees Ferry, the following things occur before it starts moving down the Colorado River: basic data are loaded; a "trip leader" is assigned (this is code that controls the behavior of the trip); and a trip agent class is assigned. Basic data are read into the simulation engine from the launch schedule contained in a master database, which includes comprehensive information such as the trip's length, method of propulsion (motor or oar), number of passengers, and the dates and locations of exchanges.

When trips are launched in GCRTSim, they are given either a Layover, or No-Layover designation, called the trip leader designation. In version 3.0 of the simulation (the current version), only private trips have the capability to engage in a layover. If a trip is private, it has $a$ chance of getting a layover designation, based on the statistical odds established from analysis of the Trip Report Database. If a private trip gets a layover leader, then it will attempt to layover at 
some point during its trip - but note that if the trip can't find an appropriate layover opportunity then it may not execute one. The probability of a Layover trip leader assignment for a private trip is dependent on the length of the trip. A trip shorter than 14 days has zero probability of doing a layover. As trip length increases, so does the probability increase (e.g., length 14 days = 0.25 , lengths 15 or 16 days $=0.50$, length 17 days $=0.66)$. These probabilities are all based on analysis of the Trip Report Database. The maximum number of times a trip with a Layover leader can layover is currently set to one, although in future versions we intend to extend this code to enable multiple layovers for certain trip types, including some commercial launches.

Upon launch, each trip is also given one of four possible agent classes (e.g. data classes) to use, dependent on the trip type. An agent class contains information and rules that govern the behavior of the trips within that class. The agent class includes, for example, mathematical functions for the how fast the trip moves based on its location along the river corridor, as well as popularity statistics regarding the attractions and camp sites. Each agent class contains different functions for trip speed, and different tables for site attraction frequency and camp frequency, all based on analysis of the Trip Report database outlined above.

\subsection{The daily plan}

Each individual trip agent has a Daily Plan function, which is first called upon at launch, and then every morning thereafter. The first thing in daily planning is to calculate the daily target cell. The daily target cell is used as a guide for roughly how far the trip should travel that day. This helps the trip travel far enough each day so that it makes its scheduled exchanges and takeout, while not traveling too far each day so that it arrives at a fixed point (an exchange or takeout date) earlier than scheduled. As a trip moves down the river, its daily target cell is 
calculated by simple equations that take into account the trip length, current day of the trip, the days of any fixed points.

The Plan Camp function consists of two steps: setting the camp range and setting goal camps. Before discussing these steps, one must understand how the simulation uses campsite capacity data. When the simulation starts, campsite information is read in from the master database. Although our table contains capacity data for both low and high water flows (Kearsley and Quarteroli, 1997), the current version is set to use high water capacities only. The Set Camp Range function selects a list of camps to be used by the rest of the planning process. This function is somewhat complicated, because it starts with a range around the daily target cell and then potentially modifies that range - depending on the circumstances the trip may be in. It basically sets MIN and MAX camp cells and gets a list of possible camps between those cells. It takes into account the trip's size when looking for potential camps, as larger trips can't fit into smaller camps. Some adjustments of this capacity data became necessary in the calibration of the model, this will be described later.

The outcome of this step is that a list of possible camps is established after defining an acceptable range of camps surrounding the daily target cell. Next, the trip leader determines how to manage this list of possible camps. The list is sorted by camp frequency, which is a measure of the popularity of the camp location, based on the four agent classes. The leader then identifies one or two "premium camps" that the trip will be "shooting for" as the day progresses. Whether the leader identifies one or two camps depends on the size of the list of possible camps. Moreover, the program identifies the last available camp for the evening - while the artificial intelligence will work to have a trip select a camp prior to reaching this cell-number, if circumstances bring the trip to this last camp, then the trip will choose it. The leader defines the 
absolute last cell such that the trip will be prevented from passing an exchange or takeout on the wrong day -and tries to camp prior to that cell. The trip leader is now ready to plan for daily activities.

Activities range from hiking, swimming, visiting archeological sites to simply spending time off river. GCRTSim distinguishes key attraction site activities from normal activities. With normal attraction sites, when the trip arrives at the site, the decision to stop and engage in the activity is complex. The trip must consider its daily progress towards camp, the situational crowding at the site, etc. For sites that are not designated as key attraction sites, the odds of stopping if another group is present are quite low. In order for the simulated agents to behave appropriately, the decision to stop will take crowding into consideration for attraction sites that are less popular than the key ones.

To summarize, the major steps in the fairly complex Plan Activity function are the following: 1) Define a range of cells within which the trip can engage in activities - this would be between the current cell and the target camp cell; 2) Obtain the list of all attraction sites in that range; 3) Store the number of "key activity sites" that are available for the trip in that range; 4) Sort the available sites using statistical preference data (highest to lowest attraction frequency); 5) Estimate the amount of time the trip has available to spend on activities; 6) Determine the number of activities to plan for, given the time available and the statistical time normally spent at an attraction site; 7) Loop through the list of possible activity sites from and randomly designate planned activity sites until either all activities are planned, or the planned time budget is spent.

Trips with a layover leader behave differently from trips that won't be having a layover. Planning is nearly identical except there are four steps: 1) Calculating the daily target cell, 2) 
Looking for "Very High" (very popular) Layover camps, 3) Planning a camp, and 4) Planning activities. The master database contains a table called "Layover Probabilities". Each camp site is assigned how attractive it is as a layover camp (LOW, MEDIUM, HIGH, VERY_HIGH, or left blank when too little data was available to make a judgment). These labels were based on an expert boaters opinion. A description of how these Layover Probabilities play into decision making is described below.

\subsection{Trip artificial intelligence: Carrying out the plan}

As detailed above, the No-Layover leader sets a list of camps and desired activity sites prior to each day's push-off onto the river. When the trip starts moving, GCRTSim calls the "Decide if Stopping here" function at each and every site defined in the mater database and effectively asks the leader if they will stop there. At each decision point, the leader first checks to see if the trip is flagged to make an exchange there, and stops if affirmative. If the trip is currently on its way to a special goal (meaning the trip has an exchange or takeout first thing in the morning) then the trip will suspend checking individual sites until after that goal has been met. Otherwise, the trip leader checks to see if the trip desires to camp at the location.

\subsection{Campsite selection}

There are several rules that affect the camping decision. The trip tries to find an attractive, unoccupied camp that is on its list of potential camps (e.g. within a reasonable range of river miles for that particular trip), although camping typically only occurs after the trip has spent some time engaged in off-river activities. The preference of expert river guides is to choose a camp within four hours prior to nightfall. A sunset function is called to determine the earliest 
and latest time to select a camp (although conditions can arise that force this guideline to be modified.)

Note the each trip type (long oar, short oar, long motor, and short motor) has affiliated with it statistical data that describe the attractiveness of each potential campsite to that particular trip type. As a trip progresses through the day, it evaluates the potential of the camps it encounters. The camp-select logic proceeds as follows: first, the trip checks to see if another trip is already camping at the site. If the camp is available, then the trip checks to see if the site is considered a premium site (based on if the site is a top camp site as defined in the data classes). A premium campsite that is available is taken, regardless of the time of day. If it is not a premium campsite, then the trip decides whether or not it wants to take it. The trip won't camp there if it has not participated in at least two daily activities or if it has more than 15 minutes left to spend on daily activities and still has planned camps left on its list. The parameter that a trip desires to complete two activities a day is based on the Trip Report analysis, but can be modified for calibration of the model. If the trip arrives at the camp after having engaged in two or more daily activities or having no more activity time left, then it looks to see how many premium camps are left on the planning list. If there are more premium sites on the list downstream, then the trip passes up this camp and moves down river. If not, then the trip weighs how "risky" it would be to pass up the camp under consideration. Trips want to minimize having to share camps or having to choose unattractive camps. If the trip arrives at the last planned camp (for that day) and finds it available, it will take it. A trip finding itself in this situation implies that the campsites in the daily plan were already chosen by other parties (occupied upon arrival, or negotiated away during a trip-to-trip communication). If even this last planned camp is occupied, the trip will first check to see if it could possibly go further downstream (check the 
time of day and the "absolute last camp cell"); if it can't go further then the trip will share the camp. If the trip doesn't have to stop here, it will continue downstream. Once a trip finds itself past the cell of its last planned camp, it will proceed to take the next available camp, without consideration of its attractiveness. The trip will keep moving until it reaches the absolute last camp cell. If the current cell is the one previously identified as the absolute last camp cell, then the trip will camp there even if it has to share the camp (note that they try to select a camp prior to getting into this position, so this rarely occurs).

\subsection{Activity selection}

Part of daily planning is to create a budget of time to spend on activities - the time needed to row or motor on-river to the campsite is estimated in the morning (it can only be estimated since only a range of campsites is pre-determined) and subtracted from the time between the morning departure and the estimated camp time. Another part of daily planning is to pre-select some activities and to reserve time from the time budget for those particular activities. The time reserved is based on the average amount of time spent at the site by that agent class.

If a trip arrives at a site where it has planned to engage in an activity, the trip will choose to stop there if it has at least fifteen minutes left in its time budget (hopefully, the amount of time budgeted for the visit still remains available). If the site was identified as a top activity site (as defined in the trip's data class), the trip will stop regardless of crowding. When the location is a planned stop and another party is already engaged in an activity there, the trip will not stop. This decision algorithm is based on expert interviews. In future versions of the model, it will be made 
more sophisticated in that some attraction sites with long hikes can be shared, as the parties will rarely see each other.

The amount of time spent at an attraction site is not the pre-estimated time reserved in the daily time budget, it is determined after deciding to stop. At any given time during the day, some time has been spent both on and off river. Communication with other river trips may have resulted in a modification of the target camp cell. A recalculation based on the time needed to get to the target camp cell, based on the current time, is necessary in order to determine how much time remains available for an activity stop.

\subsection{Running simulations}

To run GCRTSim, each individual trip requires twenty four unique parameters -- such as the number and type of watercraft, the number of passengers, any exchange information and takeout information. Before a simulation can be initiated, the user must specify any modifications to the environment that are desired. The user can disallow exchanges or shut down sites to activities and/or camping. The park managers might be concerned that a site is being over-used, or they might want to restrict people from visiting there during a critical nesting period for, for example, the willow fly catcher (an endangered bird). GCRTSim provides a powerful tool for park managers to see how competition for campsites plays out in the event that they choose to restrict camping.

Once the launch schedule and restrictions have been entered, the simulation runs. It takes approximately 10 minutes to run one season's simulation on a $500 \mathrm{MHz}$ computer. We recommend running at least ten simulations and then using our algorithm to select the one 
simulation output database that is the most typical and the most representative. Analysis of this output can then be conducted.

Once the simulation is complete, there are several ways to assess the quality of the launch schedule. In addition to the standard queries, there is also a summary report that judges the quality of the launch schedule based on criteria established in the Colorado River Management Plan (1989). These criteria judge qualities such as the percentage of time a trip spent in contact with other trips.

\section{Calibration and validation}

The calibration of GCRTSim version 3.0 was conducted in order to get simulation runs of the historical 1998 and 1999 launch calendars to match, as closely as possible, the real world data collected in the Trip Reports. Calibration basically involved running multiple simulations and conducting comparisons between the output and the real-world data. When discrepancies were found, modifications to the AI algorithms or adjustments to the parameters in the code was addressed.

GCRTSim provides analysis tools that allow one to graph the average behavior of a certain type of trip and compare the real data (from the Trip Reports) with the simulated data. For example, the early simulation runs had trips moving more slowly down the river than they should have been. Steps were taken to determine what mechanisms might result in a slowed down trip pace. We verified that both our boat speed functions and that the statistical analysis of attraction site and campsite probabilities were accurate. Further analysis revealed that trips were choosing campsites earlier in the day than the real data suggested. We modified our algorithms to get the trips to travel more miles each day before selecting a campsite. We also improved our 
logic for determining how trips budget their time among activities. Subsequent runs of GCRTSim resulted in excellent matches between the simulated and real behavioral patterns.

In Figure 2, one can both see how well calibrated GCRTSim is to the real data, as well as the results of an experimental simulation run. Figure 2 compares the "average profile" for trips of length 15 days. The horizontal axis marks the trip day number and the vertical axis marks the river mile where they camped. Three different launch scenarios are represented here: the real data from the Trip Reports diaries, the regular launch schedule showing 100\% use, and an experimental launch schedule with a 50\% reduction in trips. The close similarity between the real data and the simulated $100 \%$ use data illustrates the success of GCRTSim in replicating river trip behavior as described to us in the Trip Report diaries. While the experimental launch schedule that has a 50\% reduction in trips was speculative at best, Figure 2 shows how a user engaged in such pursuits would be able to compare the results of their simulation with the real data or a simulation of $100 \%$ use.

Time spent at attraction sites was initially calculated by sorting the Trip Report records into the four agent classes and computing the average time (and standard deviation) spent at the site. We were able to calibrate the model further by recognizing that some attraction sites offer two hiking options - a short hike and a long hike. In the current version of GCRTSim, the probability that a trip chooses the short or long hike is based on a statistical analysis of the Trip Report database based on trip type. This addition has improved the simulation of time spent at certain attraction sites.

As another example of calibration, GCRTSim uses beach capacity numbers that are $150 \%$ of those reported (Kearsley and Quarteroli, 1997). Conversations with the authors of this study revealed that the capacity figures they reported are rough approximations that could easily 
be adjusted up or down liberally. This is in part because of the differences in social group dynamics - sometimes people like to spread out when camping and sometimes they prefer to camp closer together. Extensive communication with river experts revealed that several campsites used by large groups were classified differently in the beach capacity studies. Without our adjustment in GCRTSim, testing found that larger trips (more than 30 people) seemed to be inaccurately modeled, as they would have far fewer camps available to them than was believed realistic.

A final example of calibration and testing relates to the ability of GCRTSim to experiment with the management of recreational use. The program offers the ability to restrict camping and/or attractions at any number of sites. This tool was instrumental in fine-tuning the program, as we could shut down various portions of the river and see if the resultant behavior of the trip made sense. Testing the extreme cases - shutting down so many sites that trips couldn't find a campsite - offered valuable insight into the accuracy and power of the simulation engine. Model validation will continue. Simulation outputs have been carried by park personnel on river trips in order to compare the times and locales of encounters between groups. The true launch calendar has been loaded into GCRTSim and simulations are planned for comparison against the real-world data contained in the Trip Reports. The results of the on-going model validation process, as well as additional graphs showing simulation output, are available at http://mathcs.holycross.edu/ croberts/research

\section{Discussion and conclusions}

The Grand Canyon River Trip Simulator is a comprehensive computer simulation package that integrates agent-base modeling, artificial intelligence, and statistical analysis. It 
consists of a database and a simulation engine, joined by a user-friendly interface. GCRTSim models the complex human-environment interactions, including decision-making processes at multiple scales. In addition to its tools for analyzing the linked empirical database and simulating the behavioral patterns of river rafting trips, GCRTSim also permits the user to set up new scenarios and visualize the results. Thus, it provides a means for both researchers and various stakeholders to experiment with their ideas on management issues. For example, if someone wants to try to increase the user-day allocations in order to provide greater access to the river, the user can create an experimental launch schedule. The results will show how the increased use plays out in terms of competition for quality campsites and congestion at the key attraction sites. If someone wants to experiment with reducing the group sizes, for example, then GCRTSim will be able to predict if more groups will double-camp at the larger campsites because all the smaller campsites will be occupied. If someone wants to investigate a scenario with no motorized trips, then GCRTSim will provide insight into the resulting dynamics on the river.

The Grand Canyon River Trip Simulator provides a needed tool to better inform the decision-making process for managing the Grand Canyon National Park, and offers an example of using relatively new modeling techniques (e.g., agent- and artificial intelligence-based methods) to study the complex dynamics of human-environment interactions. The general approach used in GCRTSim may be useful for modeling a variety of ecological systems in which decision-making processes need to be considered explicitly. To obtain a copy, view the help manual and view multiple results from simulation analysis, see the website at http://mathcs.holycross.edu/ croberts/ research 


\section{Acknowledgements}

GCRTSim is the result of collaboration between the National Park Service, School of Natural and Renewable Resources at the University of Arizona (U of A) and Department of Mathematics and Statistics at Northern Arizona University (NAU). Specifically, the authors would like to acknowledge the contributions of the individuals from U of A (Randy Gimblett, Terry Daniel, Susan Cherry, Michael Meitner, Dana Kilbourne), NAU (Michael Ratliff, Rian Bogle, Robert Allred, Katherine Horak, Stephanie Potter, Rob Noonan), Grand Canyon National Park Science Center (Linda Jalbert, Laurie Domler), and many others from Grand Canyon River Outfitters Association, Grand Canyon Private Boaters Association, and Grand Canyon River Guides Association. Funding for this project was from the Grand Canyon National Park through the U.S. Department of the Interior, U.S. Bureau of Reclamation, as well as other sources within NAU and $\mathrm{U}$ of $\mathrm{A}$.

\section{References}

Anderson, J., Evans, M., 1995. A Generic Simulation System for Intelligent Agent Designs. Applied Artificial Intelligence, 9 (5), 527-562.

Ball, G. L., 1994. Ecosystem Modeling in GIS. Environmental Management, 18 (3), 345-349.

Berry, J.S., Belovsky, G., Joern, A., Kemp, W.P., Onsager, J., 1993. Object-Oriented Simulation Model of Rangeland Grasshopper Population Dynamics. In Proceedings of Fourth Annual Conference on AI, Simulation, and Planning in High Autonomy Systems, Tucson, AZ. September 20-22. 102-108.

Bieri, J.A., Roberts, C., 2000. Using the Grand Canyon River Trip Simulator to Test New Launch Schedules on the Colorado River. AWIS Magazine, Association for Women in Science, Washington DC, 29, 6-10. 
Bishop, I, D., Gimblett, H.R., 1999. Management of Recreational Areas: Geographic Information Systems, Autonomous Agents and Virtual Reality. Environment and Planning B. Planning and Design, 27, 423-435.

Borkan, R.E., Underhill, A.H., 1989. Simulating the Effects of Glen Canyon Dam Releases on Grand Canyon River Trips. Environmental Management, 13 (3). 347-354.

Brian, N.J., Thomas, J.R., 1984. The 1983 Colorado River Beach campsite inventory. National Park Service Division of Resource Management, Grand Canyon National Park, Grand Canyon, $56 \mathrm{pp}$.

Briggs, D., Westervelt, J., Levi, S., Harper, S., 1996. A Desert Tortoise Spatially Explicit Population Model. Third International Conference. Integrating GIS and Environmental Modeling. January 21-25. Santa Fe, New Mexico.

Cavendon, L., Rao, A., Wobcke, W. (eds). 1997. Intelligent agent systems. Theoretical and practical issues. Lecture Notes in Artificial Intelligence. Springer-Verlag, Berlin, 188 pp. Colorado River Management Plan. 1989. National Park Service, U.S. Department of the Interior. Drogoul, A., Ferber, J. 1995. Multi-Agent Simulation as a tool for studying emergent processes. In Gilbert and Doran (eds), Simulating Societies: The computer simulation of social phenomena. UCL Press. 127-142.

Findler, N.V., Malyankar, R.M., 1995. Emergent Behavior in societies of heterogeneous, interacting agents; alliances and norms. In Gilbert and Conte (eds), Artificial Societies: The Computer simulation of social life. UCL Press. pp. 212-236.

Forrest, S., Jones, T., 1994. Modeling complex adaptive systems with Echo. In Russel J. Stonier and Xing Huo Yu. (eds), Complex Systems. Mechanism of Adaptation, IOS Press, 3-20.

Gimblett, H.R., Ball, G.L., Guisse, A.W., 1994. Autonomous Rule Generation and Assessment for Complex Spatial Modeling. Landscape and Urban Planning Journal. 30, 13-26.

Gimblett, H.R., Durnota, B., Itami, R.M., 1996a. Spatially-Explicit Autonomous Agents for Modeling Recreation Use in Complex Wilderness Landscapes. Complexity International Journal, 3 (no page numbers, online journal).

Gimblett, H.R., Itami, R.M., Durnota, B., 1996b. Some Practical Issues in Designing and Calibrating Artificial Human Agents in GIS-Based Simulated Worlds. Complexity International Journal, 3 (no page numbers, online journal). 
Gimblett, H.R., Itami, R.M., Richards, M.. 2000a. Simulating Wildland Recreation Use and Conflicting Spatial Interactions using Rule-Driven Intelligent Agents. In H.R. Gimblett (ed), Integrating GIS and Agent based modeling techniques for Understanding Social and Ecological Processes, Oxford Press, London.

Gimblett, H. R., Roberts, C.A., Daniel, T., Mitner, M., Cherry. S., Kilbourne, D., Ratliff, M., Stallman, D., Bogle, R., 2000b. Intelligent Agent Modeling for Simulating and Evaluating River Trip Scheduling Scenarios for the Grand Canyon National Park. In H.R. Gimblett (ed), Integrating GIS and Agent based modeling techniques for Understanding Social and Ecological Processes, Oxford Press, London, 245-275.

Goodchild, M., Parks, B.O., Steyaert, L.T., 1993. Environmental Modeling with GIS. Oxford University Press, 1993.

Green, D. G. 1987. Spatial Simulation of fire in Plant Communities. In P. Wise (ed), Proceedings of National Symposium on Computer Modeling and Remote Sensing in Bushfire Prevention, Canberra, Australia, 36-41.

Hall, T., Shelby, B. 2000. Evaluating Social Conditions on the Colorado River in the Grand Canyon: Effects on Experiences and Changes Over Time. Resource File in Grand Canyon Science Center, Grand Canyon National Park.

Hiebeler, D. 1994.The Swarm Simulation system and individual-based modeling. In J. Michael Power, Murray Strome, and T.C. Daniel (eds), 17th Annual Geographic Information Seminar and the Resource Technology '94 Symposium, 1, 474-494

Itami, R.M. 1988. Cellular Worlds: Models for Dynamic Conceptions of Landscapes. Landscape Architecture, 78 (5), 52-57.

Itami, R. M. 1994. Simulating Spatial Dynamics: Cellular Automata Theory. Landscape and Urban Planning, 30. 27-47.

Jalbert. L. M. 1993. Colorado River Management; Resource Monitoring Program: Recreational Impacts to Camp and Attraction Site Quality, River Rehabilitation and Visitor Experience, Program Summary. Resource File in Grand Canyon Science Center, Grand Canyon National Park. 14p.

Jones, T., Forrest, S., 1993. An Introduction to SFI Echo. Technical Report, Santa Fe Institute, Santa Fe, New Mexico. 
Kearsley, L., Quartaroli, R., 1997. Effects of a beach/habitat building flow on campsites in Grand Canyon: Final Report of Applied Technology Associates for the Glen Canyon Environmental Studies, $18 \mathrm{p}$.

Langton, C., Minar, N., Burkhart, R., 1995. The Swarm Simulation System: A tool for studying complex systems. Santa Fe Institute, Santa Fe, New Mexico.

Manneville, P., Boccara, N., Yichniac, G.Y., Bidaux, R., 1989. Cellular Automata and Modeling of Complex Physical Systems._Springer, New York.

O'Brien, Gary, Roberts, C.A., 2000, unpublished report. Evaluation of river beach carrying capacity information utilized by the Grand Canyon River Trip Simulator: Analysis and recommendations for future study. Paper can be found posted at: http://mathcs.holycross.edu/ croberts/research.

Roberts, C.A., Gimblett, H.R., 2001. Computer Simulations for Rafting Traffic on the Colorado River. Proceedings of 5th Biennial Conference of Research on Colorado Plateau, US Dept. Interior, U.S. Geological Survey, 38-50.

Saarenmaa, H., Perttunen, J., Vakeva, J., Nikula, A., 1994. Object-oriented modeling of the tasks and agent in integrated forest health management. AI Applications in Natural Resource Management, 8 (1), 43-59.

Shechter, M., Lucus, R.L., 1978. Simulation of Recreational Use for Park and Wilderness Management. Johns Hopkins University Press for Resources for the Future, Inc., Washington, DC. 220 pp.

Slothower, R. L., Schwarz, P.A. , Johnson, K.M., 1996. Some Guidelines for Implementing Spatially Explicit, Individual-Based Ecological Models within Location-Based Raster GIS. Third International Conference Integrating GIS and Environmental Modeling. January 21-25. Santa Fe, New Mexico.

Tobler, W.R. 1979. Cellular geography. In S. Gale and G. Olsson (eds), Philosophy in Geography, 379-386.

Underhill, A. H., Xaba, A.B., 1983. The Wilderness Simulation Model as a Management Tool for the Colorado River in Grand Canyon National Park. Technical Report 11. CPSU/UA, Tucson, Arizona. 17 pp. 
Underhill, A. H., Xaba, A.B., Borkan, R.E., 1986. The Wilderness Simulation Model Applied to Colorado River Boating in Grand Canyon National Park, USA. Environmental Management,10 (3), 367-374.

United States Geological Survey, 2001. Historical Water Release information from Glen Canyon Dam in Page, Arizona available at http://www.usgs.gov.

Weiss, G. (ed). 1999. Multiagent Systems: A Modern Approach to Distributed Artificial Intelligence. MIT Press, Cambridge, Massachusetts.

Wu, J. and Loucks, O. L., 1995. From balance-of-nature to hierarchical patch dynamics: A paradigm shift in ecology. Quarterly Review of Biology, 70: 439-466.

Wu, J. and Levin, S. A., 1997. A patch-based spatial modeling approach: conceptual framework and simulation scheme. Ecological Modelling, 101: 325-346.

Wu, J., 1999. Hierarchy and scaling: Extrapolating information along a scaling ladder. Canadian Journal of Remote Sensing, 25: 367-380. 
Table 1. Trip types based on days between Lees Ferry and Diamond Creek.

\begin{tabular}{ll}
\hline Trip Type & Days between Lees Ferry and Diamond Creek \\
\hline Short motor trips & $6-8$ days \\
Long motor trips & 9 or more days \\
Short oar trips & 14 or fewer days \\
Long oar trips & 15 or more days \\
\hline
\end{tabular}

Table 2. Trip Report statistics collected during 1998, 1999 and 2000 seasons.

\begin{tabular}{lllll}
\hline Trip type & Private & Commercial & Total & Return rate \\
\hline Short motor & 7 & 222 & 229 & $22 \%$ \\
Long motor & 9 & 18 & 27 & $32 \%$ \\
Short oar & 24 & 64 & 88 & $26 \%$ \\
Long oar & 125 & 18 & 143 & $22 \%$ \\
\hline Totals & 165 & 322 & 487 & $29 \%$ \\
\hline
\end{tabular}


Table 3. Popular attraction sites in the river corridor of the Grand Canyon National Park during the typical flow regimes of 1998 - 2000.

\begin{tabular}{llll}
\hline River Mile & \multicolumn{1}{c}{ Site Name } & Rank & Frequency \\
\hline 136.20 & DEER CREEK & 1 & 0.91 \\
156.80 & HAVASU & 2 & 0.88 \\
32.80 & REDWALL & 3 & 0.82 \\
116.50 & ELVES CHASM & 4 & 0.77 \\
61.40 & LITTLE COLORADO & 5 & 0.66 \\
87.80 & PHANTOM & 6 & 0.61 \\
108.70 & SHINUMO & 7 & 0.56 \\
147.90 & MATKATAMIBA & 8 & 0.48 \\
132.00 & STONE CK & 9 & 0.41 \\
47.20 & UPR SADDLE & 10 & 0.34 \\
31.60 & SOUTH CANYON & 11 & 0.31 \\
53.00 & NANKOWEAP & 12 & 0.3 \\
84.00 & CLEAR CK & 13 & 0.28 \\
34.80 & NAUTILOID & 14 & 0.26 \\
133.80 & TAPEATS & 15 & 0.25 \\
\hline
\end{tabular}


Table 4. Most popular camps in the river corridor of the Grand Canyon National Park during the typical flow regimes of $1998-2000$.

\begin{tabular}{llll}
\hline River Mile & Site Name & Rank Normal & Freq Normal \\
\hline 108.20 & LWR BASS & 1 & 0.2 \\
151.50 & LEDGES & 2 & 0.18 \\
136.80 & PONCHO'S KITCHEN & 3 & 0.18 \\
29.30 & SHINUMO WASH & 4 & 0.17 \\
64.70 & CARBON & 5 & 0.17 \\
93.40 & GRANITE & 6 & 0.16 \\
219.80 & UPPER 220-MILE & 7 & 0.16 \\
133.80 & TAPEATS & 8 & 0.15 \\
137.00 & BACKEDDY & 9 & 0.15 \\
91.60 & TRINITY CK & 10 & 0.15 \\
53.00 & NANKOWEAP & 11 & 0.15 \\
16.40 & HOT NA NA & 12 & 0.15 \\
109.40 & 110 MILE & 13 & 0.14 \\
81.30 & GRAPEVINE & 14 & 0.14 \\
31.60 & SOUTH CANYON & 15 & 0.13 \\
\hline
\end{tabular}




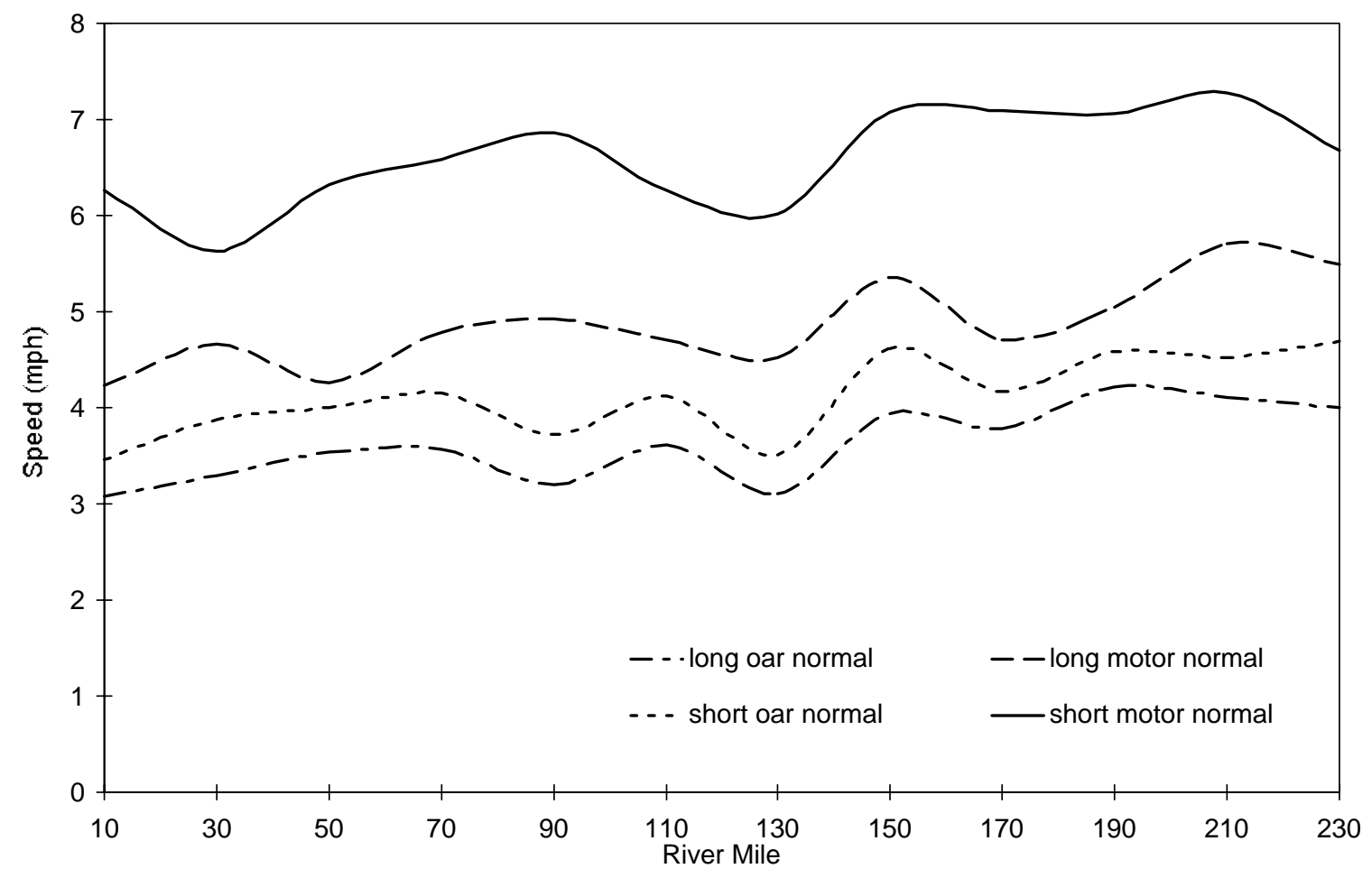

Fig. 1. Boat Speed for rafting trips on the Colorado River in Grand Canyon National Park for the period of $1998-2000$ when average water flow rate was $19,000 \mathrm{cfs}$. River mile 0 corresponds to Lees Ferry and river mile 225.7 corresponds to Diamond Creek. 


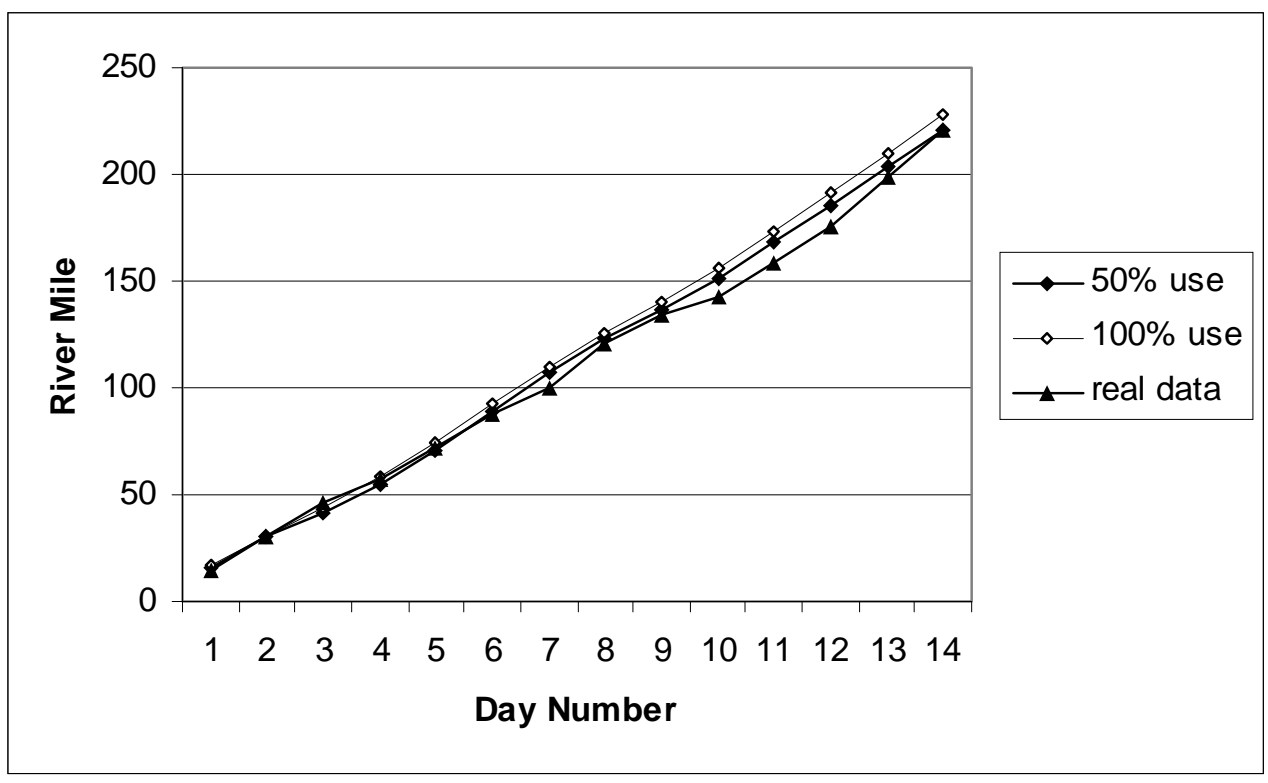

Figure 2. A comparison of the "average profile" for trips of length 15 days. The horizontal axis marks the trip day number and the vertical axis marks the river mile where they camped. Three different launch scenarios are represented here: the real data from the Trip Reports diaries, the regular launch schedule showing $100 \%$ use, and an experimental launch schedule with a $50 \%$ reduction in trips. 